\title{
Green Cycle: Sulfate Sorption from Natural Water on Anionic Clay Compound Obtained from Industry Wastewater
}

\author{
Genoveva Rosano-Ortega ${ }^{*}$, Carlos Vega Lebrún ${ }^{1}$, Juan M. López Oglesby ${ }^{1}$, \\ Sonia Martínez Gallegos ${ }^{2}$, Daniel Cruz-González ${ }^{3}$, Beatriz Pérez Armendariz ${ }^{1}$ \\ ${ }^{1}$ Research Department, Universidad Popular Autónoma del Estado de Puebla (UPAEP), Puebla, México \\ ${ }^{2}$ Division of Graduate Studies and Research, Instituto Tecnológico de Toluca, México City, México \\ ${ }^{3}$ Chemical Engineering Faculty, Benemérita Universidad Autónoma de Puebla, Puebla, México \\ Email: "genoveva.rosano@upaep.mx
}

Received January 18, 2013; revised February 20, 2013; accepted February 28, 2013

Copyright (C) 2013 Genoveva Rosano-Ortega et al. This is an open access article distributed under the Creative Commons Attribution License, which permits unrestricted use, distribution, and reproduction in any medium, provided the original work is properly cited.

\begin{abstract}
In this paper we are describing a green cycle process. The first step was a novel hydrotalcite-like compound (HTLC) synthesized by a co-precipitating method, under standard ambient temperature and pressure, using chemical industry wastewater rich in divalent and trivalent cations, activated by a thermal treatment and finally characterized by scanning electron microscopy (SEM), energy dispersive X-ray fluorescence (EDS) and thermogravimetric analysis (TGA). The second step was a series of batch sorption tests performed with this activated HTLC and untreated underground sulfurous water from the state of Puebla, México. The HTLC calcined at $500^{\circ} \mathrm{C} / 3 \mathrm{~h}$ exhibited the best sorption ability for ions, demonstrated a decrease of the hardness and sulfate ions to below the regional legal standards for drinking water. Once inactive after being used in water treatment, the sorbed ions were removed by ion exchange in a carbonate-containing solution, resulting in an $80 \%$ recycling of the material which upon activation demonstrated a retained capacity for water treatment. This recyclability suggests the exciting possibility of this novel compound as an efficient "green" technology in water treatment processes.
\end{abstract}

Keywords: Hydrotalcite-Like Compound; Wastewater; Sulfurous Underground Water; Ion Sorption; Green Cycle

\section{Introduction}

Underground water in the State of Puebla, México is characterized by a slightly acidic $\mathrm{pH}(\sim 6.5)$, high hardness $\left(\sim 1200 \mathrm{mg} / \mathrm{L} \mathrm{CaCO}_{3}\right)$ and the presence of sulfurous chemical species mainly as sulfate ions such as $\mathrm{SO}_{4}^{2-}$ $(\sim 950 \mathrm{mg} / \mathrm{L})$ and $\mathrm{H}_{2} \mathrm{~S}(\sim 8.0 \mathrm{mg} / \mathrm{L})$, which give the water an unpleasant odor and flavor. This is particularly a problem in areas of volcanic activity where in many cases the drinking water contains traces of sulfurous compounds, even after standard purification. Purification treatments which address this lingering problem must be able to process large amounts of water at low cost to be effective [1].

Layered double hydroxides (LDH) or compounds are referred to in this paper as hydrotalcites (HT) or anionic clays. From the general formula for HT, $M(\mathrm{II})_{1-x} M(\mathrm{III})_{x}$ $(\mathrm{OH})_{2}\left(A^{n-}\right)_{x / n} m \mathrm{H}_{2} \mathrm{O}$ [2-5], the crystal structure of these

\footnotetext{
"Corresponding author.
}

LDH (Figure 1) consists of positively-charged brucitetype main sheets which forms an octahedron as a subunit of a layered structure of HT, where partial replacement of divalent $M$ (II) with trivalent metal ion $M$ (III) in the brucite-type structure results in an excess of positive charge, which is compensated in the HT structure by an n-valent anion $\left(A^{n-}\right)$ and $x$ can have values between 0.2 and 0.33 . These anions such as carbonate, sulfate and hydroxide (which may also be hydrated) can be introduced between the layers of the crystal structure. The

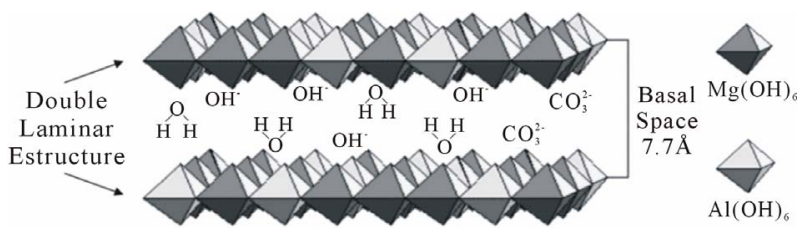

Figure 1. Interlayer hydroxides in an $\mathrm{LDH}$ with the general formula: $\left[M(\mathrm{II})_{1-x} M(\mathrm{III}) \mathbf{x}(\mathrm{OH})_{2}\right]^{+x}\left[A^{\mathrm{n}-}{ }_{\mathrm{x} / \mathrm{n}} \mathrm{zH}_{2} \mathrm{O}\right]^{-x}$. 
anions and water molecules introduced into interlayer spaces are only weakly bonded to the crystal layers. Therefore, HT can be used as an anion exchanger, polymer stabilizer, antacid anion scavenger and adsorbent [6-8].

The preparation of anionic clays has been described vastly in the literature [9-12]. Two important reviews of anionic clay chemistry were published in which the synthesis methods available for anionic clay synthesis have been summarized [13,14]. HT activation takes place through thermal decomposition by heating HT in air up to $500^{\circ} \mathrm{C}$. This causes it to be calcined into periclase-like compounds (Mg-Al oxide) which possess a well-known "memory effect" or the ability to reconstruct themselves to their original structure when it is exposed to water [14].

In general, crystalline HT compounds are excellent adsorbents for a variety of anions in many different applications $[15,16]$. Nevertheless, they are relatively expensive due to the purity required of the reagents and complexity of the synthesis conditions. Special activation steps like calcination increase the intricacy and costs of the synthesis process even more [17]. An objective of the present work was to give an alternative called "green cycle" in which a novel method for the synthesis of an HTLC suitable for the adsorption of sulfate ions from sulfurous water was provided. A further requirement was that the processes not involve expensive reagents or complicated synthesis steps allowing the HTLC to be produced in a cost-efficient manner. This goal was achieved by taking advantage of a wastewater byproduct from a chemical industry, which has an excess of $\mathrm{Mg}^{2+}$ and $\mathrm{Al}^{3+}$ ions.

\section{Experimental Details}

\subsection{Synthesis of $\mathrm{Mg}-\mathrm{Al}-\mathrm{CO}_{3} \mathrm{HTLC}$}

Commercially, bleaching earths are provided by extracting naturally-occurring clays, which contain a variety of different metals like $\mathrm{Na}, \mathrm{K}, \mathrm{Ca}, \mathrm{Mg}, \mathrm{Al}$ and $\mathrm{Fe}$, with strong mineral acids. During the extraction process, some of these metals are dissolved from the clay mineral and form a cation-rich acid solution (wastewater) which needs treatment. The acid-treated clay may be used as a bleaching earth for the treatment of edible oils or as catalyst material. Due to the high relevance of bleaching earths in many industrial applications and their economic value, the cation-rich byproduct solution is highly available and inexpensive [18].

The HTLC with carbonate as the interlayer anion referred in this paper were prepared following a standard co-precipitation method [19]. The acid extract obtained in the production of bleaching earth from an industrial manufacturer in Puebla, Mexico, was selected as a by- product such that it contained at least $6.5 \mathrm{~g} / \mathrm{L} \mathrm{Al}^{3+}$ ions and $4.5 \mathrm{~g} / \mathrm{L} \mathrm{Fe}^{3+}$ ions, both calculated as elemental $\mathrm{Al}$ and Fe. Generally, the clays used as the starting material in the production of bleaching earths also contain $\mathrm{Mg}^{2+}$ ions which are extracted during the treatment of the clay with strong mineral acids. Therefore, in most cases only a small amount of $\mathrm{Mg}^{2+}$ ions must be added to adjust the concentration of the acid extract to at least $6.8 \mathrm{~g} / \mathrm{L} \mathrm{Mg}^{2+}$, allowing a range of 6.8 to $25 \mathrm{~g} / \mathrm{L}$ for the final solution, calculated as elemental $\mathrm{Mg}$. This corresponds to the difference in $\mathrm{Mg}$ concentration in the acid extract and the adsorbent to be synthesized [20].

The wastewater solution used for the laboratory synthesis of the HTLC corresponded to a typical bleaching earth extract: it contained $9.7 \mathrm{~g} / \mathrm{L}$ of $\mathrm{Al}^{3+}$ and $20 \mathrm{~g} / \mathrm{L}$ of $\mathrm{Mg}^{2+}$, as determined by Inducted Couple Plasma (ICP, Table 1). In a three-necked flask equipped with a stirrer, $1 \mathrm{~L}$ of cation-rich wastewater was mixed with $20 \mathrm{~mL}$ of a $20(\mathrm{wt} \%)$ solution of $\mathrm{Mg}(\mathrm{OH})_{2}$ at $600 \mathrm{rpm}$, the $\mathrm{pH}$ value ( $\mathrm{pH} 20$ Conductronic electrode) was adjusted to 7 with a 20 (wt $\%) \mathrm{NaOH}$ solution. After that, $800 \mathrm{~mL}$ of a 15 (wt\%) $\mathrm{Na}_{2} \mathrm{CO}_{3}$ solution was added to reach a $\mathrm{pH} 10$. Finally, the stirring speed was increased to $1800 \mathrm{rpm}$ and the solution was stirred for $30 \mathrm{~min}$. A solid precipitate was formed which was named HT3015D.

To optimize the previously-mentioned laboratory method and test the technical synthesis methodology for an expansion to the industrial level-production of HT3015D using the cation-rich wastewater, the composition shown in Table 1 was used. The synthesis was carried out on a pilot scale as follows: The solution was heated to $60^{\circ} \mathrm{C}$ and then $98 \mathrm{~g}$ of $\mathrm{Mg}(\mathrm{OH})_{2}$ (aqueous solution, $20 \mathrm{wt} \%$ ) was added dropwise under high-shear agitation that supported an uniform product-forming process and prevented an early agglomeration-flocculation. During addition of the $\mathrm{Mg}(\mathrm{OH})_{2}$ solution the temperature of the mixture was kept at $60^{\circ} \mathrm{C}$ during 10 min of agitation. Thereafter, for all the trials reported for further on in the

Table 1. Technical information by ICP of an industry wastewater from the bleaching earths process.

\begin{tabular}{cc}
\hline Analysis & Values \\
\hline Acidity, $\mathrm{g} \cdot \mathrm{L}^{-1}$ & $35.5-45.0$ \\
$\mathrm{pH}$ & $<1$ \\
Density at $20^{\circ} \mathrm{C}, \mathrm{g} \cdot \mathrm{cm}^{-3}$ & 1.09 \\
Solid content, $\%$ & $<0.3$ \\
Composition, $\mathrm{g} \cdot \mathrm{L}^{-1}$ & \\
$\mathrm{Al}^{3+}$ & 9.7 \\
$\mathrm{Fe}^{3+}$ & 4 \\
$\mathrm{Ca}^{2+}$ & 2.3 \\
$\mathrm{Mg}^{2+}$ & 20 \\
$\mathrm{Colloidal} \mathrm{Silica}$ & 0.3 \\
\hline
\end{tabular}


paper, an alkaline solution was dropwise added, until the $\mathrm{pH}$ reached 7 by using $\mathrm{NaOH}$ solution (10 - $30 \mathrm{wt} \%)$. Though not used here, other solutions such as $\mathrm{KOH}$, $\mathrm{Ca}(\mathrm{OH})_{2}$ or $\mathrm{Mg}(\mathrm{OH})_{2}$ can be used as a base to neutralize $\mathrm{Al} / \mathrm{Mg}$ source mixture. During adjustment of the $\mathrm{pH}-$ value a precipitate containing metal ions was produced. To achieve complete precipitation of the metal ions, solution of $\mathrm{Na}_{2} \mathrm{CO}_{3}(20 \mathrm{wt} \%)$ was added a until the $\mathrm{pH}$ reached 10. Again, though not used here, other solutions such as $\mathrm{NaHCO}_{3}, \mathrm{~K}_{2} \mathrm{CO}_{3}, \mathrm{KHCO}_{3}, \mathrm{Ca}\left(\mathrm{HCO}_{3}\right)_{2}, \mathrm{MgCO}_{3}$ and $\mathrm{Mg}\left(\mathrm{HCO}_{3}\right)_{2}$ in pure form or as aqueous solutions with a solid content within a range of 10 to $25 \mathrm{wt} \%$ can be used to form the precipitate. The mixture was kept at $60^{\circ} \mathrm{C}$ for one hour while continuing high-shear agitation, then cooled to room temperature and then filtered through a Buchner funnel. To remove sulfate impurities from the $\mathrm{H}_{2} \mathrm{SO}_{4}$ bleaching earth process, the precipitates were washed 5 times with $500 \mathrm{~mL}$ tap water that did not exceed the regional legal standards for drinking water quality, then placed on a glass dish and dried at $120^{\circ} \mathrm{C}$ in an oven. The dried solid was milled and sieved through a $75 \mu \mathrm{m}$ mesh to reach the desired particle size. This dehydrated solid precipitate was named HT3015O.

Finally, both solid samples synthesized HT3015D and HT3015O, with $x=\left(\mathrm{Al}^{3+} / \mathrm{Al}^{3+}+\mathrm{Mg}^{2+}\right)=3$, were calcined for activation by heating at $500^{\circ} \mathrm{C} / 3 \mathrm{~h}$, obtaining HT3015DT and HT3015OT, respectively, where these periclase-like compounds or metallic oxides (Tan et al. 2011) were utilized for the sulfurous underground water treatment.

\subsection{Sorption Test}

Sorption batch tests were carried out with a ratio of 2:0.01, 2:0.02 and 2:0.03 L:Kg, using HT3015OT and sulfurous underground water with a quality described in the Introduction section. These tests were carried at room temperature and pressure conditions and stirred for $1 \mathrm{~h}$ at low shear, and then the adsorbent was separated by filtering through a paper filter. The water samples were analyzed for their $\mathrm{SO}_{4}^{2-}$ concentration by UV spectroscopy at $420 \mathrm{~nm}$. Water hardness and $\mathrm{pH}$ measurements were done by the methods described by the American Public Health Association [21].

\subsection{Characterization Techniques}

Sorption batch tests X-ray diffraction analysis (XRD) was employed to identify and characterize the species present and their degree of crystallinity of the synthesized materials. The XRD patterns were recorded using a SIEMENS D500 powder diffractometer system with $\mathrm{CuK} \alpha$ radiation $(\mathrm{K} \alpha=0.1518 \AA, 36 \mathrm{kV}, 20 \mathrm{~mA})$, a voltage of $35 \mathrm{kV}$, a current of $25 \mathrm{~mA}$, and a goniometer speed of $3 \% \mathrm{~min}$ ). The samples were scanned for $2 \theta$ val- ues ranging from $0^{\circ}$ to $75^{\circ}$.

The thermal behavior data were obtained on TGA51 TA Instruments system in a nitrogen atmosphere at 35 $\mathrm{mL} / \mathrm{min}$ and set at a heating rate of $10^{\circ} \mathrm{C} / \mathrm{min}$. SEM images and elemental contents were obtained using a highvacuum scanning electron microscope, JEOL 5900LV, operating at an accelerating voltage of $15 \mathrm{kV}$, with an OXFORD probe for energy-dispersive X-ray emission analysis (EDS).

\subsection{Recycling of the HT3015O}

To regenerate the HT3015OT used in sorption tests as a HTLC carbonated for recycling, an ionic exchange of the sulfates ions trapped in the lamelar structure of HT was performed with an oversaturated-carbonates ionic solution of $\mathrm{Na}_{2} \mathrm{CO}_{3}$ at $\mathrm{pH} 7$. Its structure was then evaluated by XRD, re-activated at $500^{\circ} \mathrm{C} / 3 \mathrm{~h}$ and recycled for sorption tests [22,23].

\section{Results \& Discussion}

\subsection{Characterization}

HT3015D and HT3015O samples show diffraction patterns which are typical for the LDH structure (Figure 2) with sharp and symmetric reflections of the basal (003), (006) planes and broad, referred by Miyata and Okada [24]. Thermally-treated sample HT3015OT corresponded to periclase, a typical calcined product of HTLC (JCPDS 45-0946). The calculated basal spacing and lattice parameters for HT3015D showed a basal spacing d003 of $7.68 \AA$ and $7.36 \AA$ for HT3015O, and are in agreement with the values reported in the literature indicating the formation of well-crystallized HTLC, the literature data have indicated that the basal d spacing of the (003) plane is dependent on the size of the guest anion in the inter

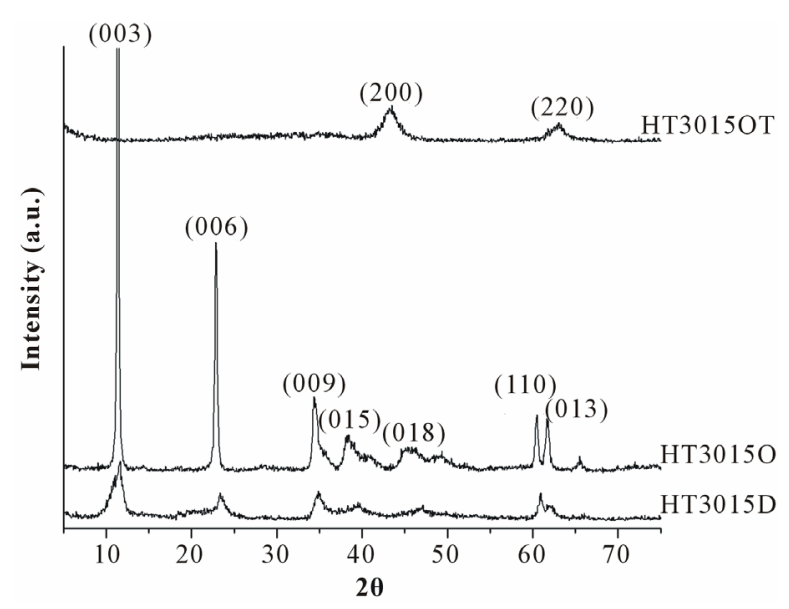

Figure 2. X-ray diffraction patterns of HTLC synthesized in the laboratory (HT3015D), optimized and synthesized at the industrial scale (HT3015O) and thermally treated for activation (HT3015OT). 
layer. These values correspond well with the most intense peak at $8.64 \AA$, determined by Miyata and Okada [24], Heraldy [25] and Alexa [8]. The increment of d003 spacing suggested major crystallinity and no other diffraction peaks were detected in any of the patterns obtained. This indicated that the $\mathrm{MgAlCO}_{3}$-type HTLC was the only crystalline-precipitated product using the cation-rich byproduct solution.

Intensity and crystalline differences were observed in the XRD patterns between HT3015D synthesized directly and HT3015O from the optimized industrial-scale process (Figure 2).

Figure 3(a) shows that the original HT3015O powder particles presented a very singular morphology: they seemed to be hollow spheres, having diameter size distribution as an average of the three consecutive measurements between $0.6 \mu \mathrm{m}$ and $2.5 \mu \mathrm{m}$. Additionally, the surface of these particles seemed to be corrugated, with seashell-like structures. In fact, this kind of morphology has been already reported for certain synthesized metal oxides [26]. Later, during the heat treatment, HTLC decomposed, producing gases $\left(\mathrm{H}_{2} \mathrm{O}\right.$ and $\left.\mathrm{CO}_{2}\right)$. Additionally, the production and release of the gases, from the core of the particles, inhibited the densification of the surfaces and produced porous materials.

For HT3015O, the mixing speed was slower than for HT3015D at all stages, and the $\mathrm{pH}$ value for HT3015O was higher than HT3015D. These two changes in the synthesis process yielded a more crystalline product, and with more intense and better-defined peaks for HT3015O.

Thermally-treated sample HT3015OT showed parts of diffraction peaks disappearing, indicating that the structure of HT began to decompose. Furthermore, the nonexistence of peak (006) also suggested the collapse of the layered structure.

From Figure 3(b), the HT3015O elemental composition was almost entirely: $\mathrm{Al}, \mathrm{Mg}, \mathrm{O}$ and $\mathrm{C}$. The $\mathrm{x}$ factor was determined with the following Equation (1):

$$
x=\frac{\mathrm{M}^{3+}}{\mathrm{M}^{3+}+\mathrm{M}^{2+}}
$$

The obtained experimental concentration values are shown as an inset in the same Figure 4, and with the value of $0.30+0.19$, which corresponded to that of $\mathrm{x}$ expected by its synthesis.

The elemental composition of HT3015OT that was exposed to sulfurous underground water for $24 \mathrm{~h}$ (Figure 4(a)) contained sulfates due to the sorption process. The main components remained the same as in the original HT3015O (Figure 4) but also included S, Ca, and some $\mathrm{Si}$. Elemental composition of the gray crystals and white spherical particles in Figure 4(b) showed that the white ones were richer in $\mathrm{Ca}$ and were attached to surface of the gray crystals.

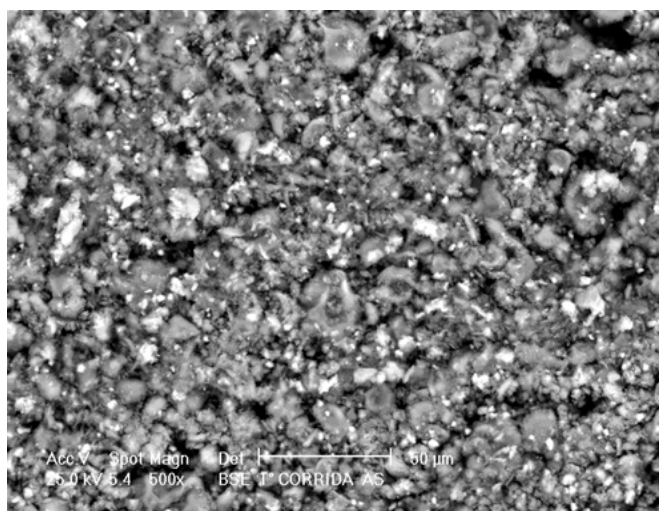

(a)

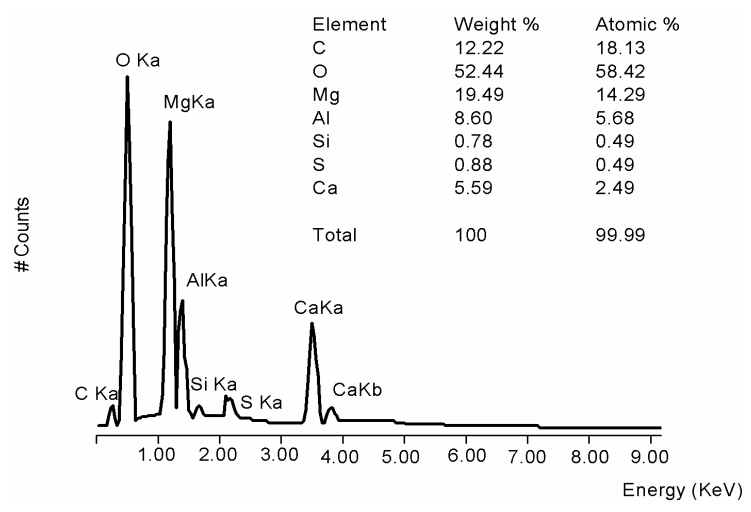

(b)

Figure 3. (a) HT3015O morphology as a seashell-like structure obtained from SEM; (b) EDS of HT3015O.

To complete the characterization study, TGA was applied to determine the high-temperature thermal stability of the samples prepared. Figure 5 shows the TGA analysis results for the HT3015D and HT3015O samples. The diagrams for the two samples synthesized are very close to those of HTLCs reported elsewhere [27]. The thermal decomposition process could be described in two consecutives overlapped steps: 1 . The mass-loss level of $9.63 \%$ was close to the theoretical value corresponding to the loss of crystal water, indicating that the main weightloss phase involved in this step was the removal of interlayer water showing an endothermic peak corresponded to $25^{\circ} \mathrm{C}$ to $200^{\circ} \mathrm{C}[28,29]$.

\subsection{Sorption Test}

Figure 6 shows the sorption tests in $20 \mathrm{~mL}$ of sulfurous water for HT3015OT. This graph shows the uptake of the main problematic elements (sulfate ions, hardness, and alkalinity) considered in this underground water for different clay loads. To make this a viable large-scale application, minimizing the required quantities of HTLC for treatment is desired while achieving the goals set by official Mexican law of $400 \mathrm{mg} / \mathrm{L}$ for sulfate ions and $500 \mathrm{mg} / \mathrm{L}$ for hardness [30]. In the tested samples, the 


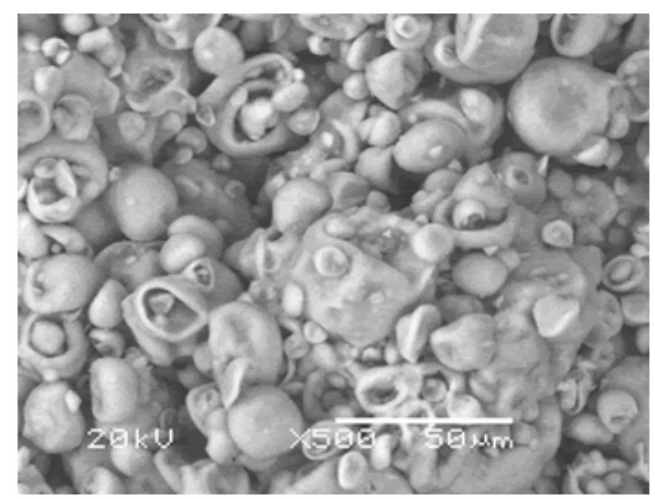

(a)

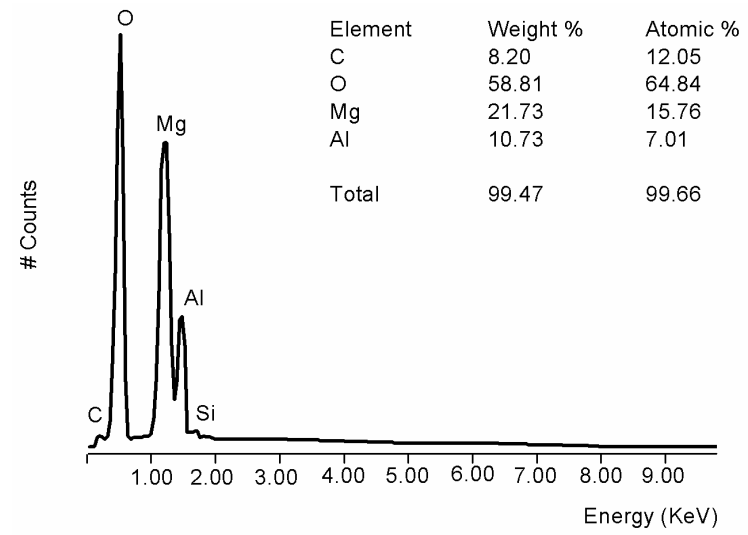

(b)

Figure 4. (a) Morphology of HT3015OT and exposed to sulfurous underground water for $24 \mathrm{~h}$; (b) EDS of HT3015OT and exposed to sulfurous underground water for $24 \mathrm{~h}$.

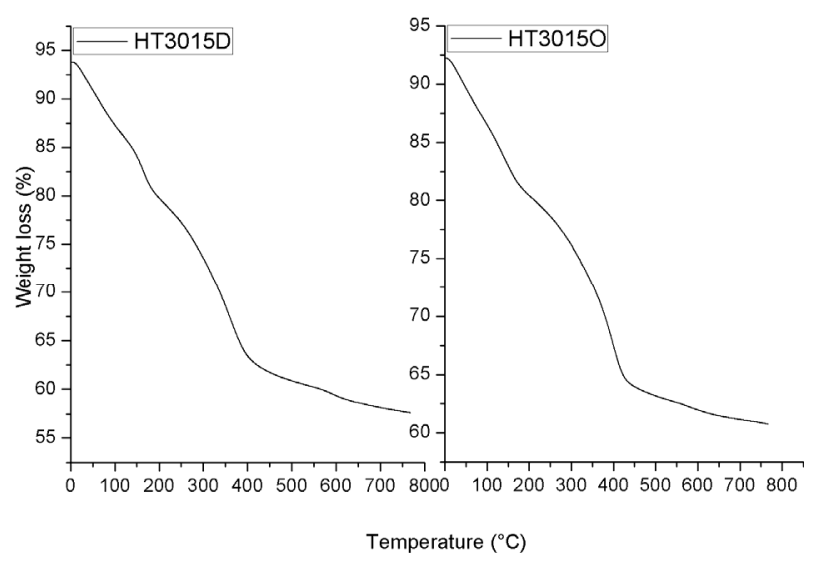

Figure 5. TGA analysis for HT3015D and HT3015O samples.

amount of HTLC employed successfully decreased the initial concentration of $\mathrm{CaCO}_{3}$ by half. For higher quantities of HTLC, $(200 \mathrm{mg} / \mathrm{L}$ of HT3015OT), the three water quality standards previously mentioned were met or exceeded. This larger concentration of clay removed up to $62 \%$ of the initial sulfate ions. In a similar fashion, alkalinity values were decreased below detectable levels

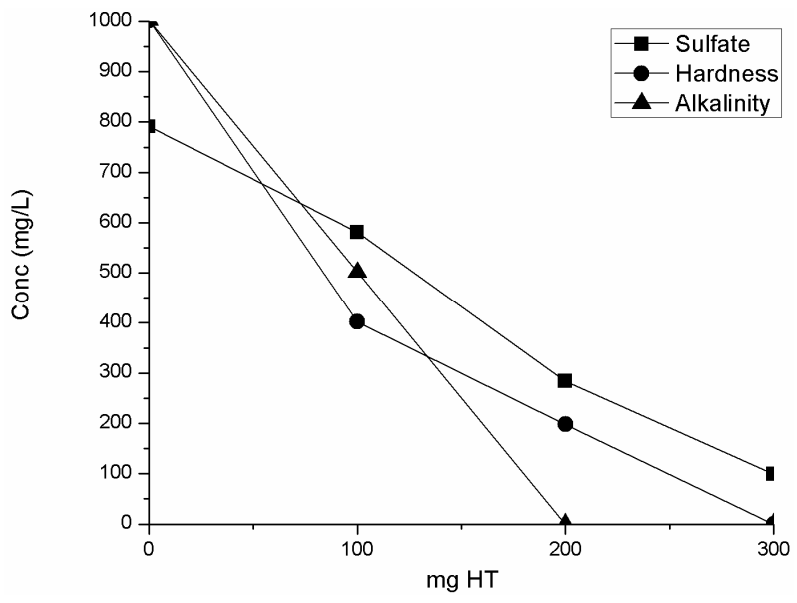

Figure 6. Sorption batch test on for sulfate, hardness and alkalinity using HT3015OT.

for the employed assays when using $200 \mathrm{mg} / \mathrm{L}$ of HT3015OT.

Adding HT3015OT to sulfate-contaminated water raised the initial $\mathrm{pH} 7$ up to 10 . It is believed this increase in $\mathrm{pH}$ helps to reduce hardness parameter. This behavior is important because the HTLCs were thought of only as means for anion exchange [31], but now we can see that it also precipitated cations. The mechanism proposed from these observations is that when HT3015OT comes in contact with the sulfurous water a catalytic activity of dissociation of the water molecules occurs $\left(\mathrm{H}^{+}+\mathrm{OH}^{-}\right)$. The mixed oxides of $\mathrm{Mg}$ and $\mathrm{Al}[\mathrm{Mg}(\mathrm{Al}) \mathrm{O}]$ started to reconstruct its crystal structure of $\mathrm{LDH}$ trapping $\mathrm{H}+$ and the hydroxides $\left[\mathrm{Mg}(\mathrm{OH})_{6}^{4-}\right]$ and $\left[\mathrm{Al}(\mathrm{OH})_{6}^{4-}\right]$ were formed. This was evidenced by the change in water's $\mathrm{pH}$ from 6 - 7 to $10-12$. Once the mixed oxides of Al and $\mathrm{Mg}$ were formed, the structure was able to trap anions $\left(\mathrm{An}^{-}\right)$present in the solution as shown by Equation (2):

$$
\begin{aligned}
& 2 \mathrm{Mg}_{3} \mathrm{AlO}_{4}(\mathrm{OH})+8 \mathrm{H}_{2} \mathrm{O}+\mathrm{SO}_{4}^{2-} \longrightarrow \\
& {\left[\mathrm{Mg}_{6} \mathrm{Al}_{2}(\mathrm{OH})_{16}\right]\left(\mathrm{SO}_{4}\right)+2 \mathrm{OH}^{-}}
\end{aligned}
$$

The removal mechanism of $\mathrm{SO}_{4}^{2-}$ from sulfurous water by HT3015OT, happened because of both the memory effect [14], during the regeneration of the lamellar structure of HTLC and the mechanism involved in diminishing hardness by the chemical precipitation of $\mathrm{CaCO}_{3}$ and to a lesser degree $\mathrm{MgCO}_{3}$ and $\mathrm{MgCa}\left(\mathrm{CO}_{3}\right)_{2}$. Because of the former it was also concluded that removal of $\mathrm{CO}_{3}^{2-}$ ions takes place through the two mechanisms mentioned, sorption and precipitation.

Sulfate sorption is due to the slow anion exchange ability of the thermally-treated HTLC, caused by reconstruction of tightly-held layers with $\mathrm{SO}_{4}^{2-}$ ions in the interlayer positions [13]. The sulfated HTLC could be explained by the memory effect because the regeneration 
of the HT structure is reversible if the calcination temperature does not exceed $500^{\circ} \mathrm{C}-600^{\circ} \mathrm{C}$. The HTLC can rehydrate and incorporate anions, sulfates in this case, in order to rebuild the initial HT lamellar structure. On the other hand, the ion exchange equilibrium constant for HTLCs is greater for divalent anions than for monovalent anions.

Table 2 indicates the real sorption capacity of HT3015OT for sulfate ions present in untreated sulfurous well water. After the three sequential treatment runs, the resultant water has been cleansed of the vast majority of the anions and cations present in the original sample, and the sulfate ions have been reduced to below the measurement threshold. The sorption capacity of this new anionic clay is very favorably compared to other reported conventional HT clay behaviors such as those reported by Parker et al. that report a $\sim 3 \mathrm{meq} / \mathrm{g}$ HT sorption capacity when prepared in carbonate-free solutions, as well as a near-total sorption of sulfates present in the materials being treated. [32] As seen in Table 2, the anionic and cationic sorption exceeds the values reported by Parker $e t$ al. Currently, the only commercially-viable method for removing sulfates from groundwater is via reverse osmosis. [33] This series of tests shows great promise for a green method of sulfate removal that has yet to be adequately implemented on an industrial scale.

\section{Conclusions}

A novel HTLC synthesized by a co-precipitating method, under standard ambient temperature and pressure, using chemical industry wastewater rich in divalent and trivalent cations was performed. Batch sorption tests with this activated HTLC and untreated underground sulfurous water from the state of Puebla, México, showed to be suitable for the adsorption of sulfate ions.

The powder X-ray diffraction patterns suggest that HT3015O is comparable to HT clays made by conventional methods. The overall process presented in this work is very flexible, enabling a wide variety of materials to be prepared with standard industrial equipment, inexpensively and in an environmental-friendly manner. The resulting HTLC proved to have a sorption capacity similar to conventional HT compounds, but generated in an ecologically-sound green chemistry process that takes advantage of existing residue products.

The use of a wastewater from the bleaching earth's process allows a very cost-efficient synthesis of the adsorbent. The presence of metal ions does not have any detrimental effect on the formation of HT and the adsorption capacity of this adsorbent, and no heavy metal ions were leached out during the treatment of sulfur water by the sorption batch tests conducted in this work.

It was found that the HT3015OT obtained is suitable for removing sulfur-containing anions from sulfurous un-
Table 2. Batch sorption of anions and cations present in sulfurous water and water recovered after treatment with the HT3015OT. A reading of N.D., represents no detectable ions with the given measurement techniques.

\begin{tabular}{|c|c|c|}
\hline CONCENTRATION & $\begin{array}{c}\text { Sulfurous } \\
\text { Water } \\
\mathbf{m e q} \cdot \mathbf{L}^{-1}\end{array}$ & $\begin{array}{c}\text { Treated Water } \\
\text { meq } \cdot \mathbf{L}^{-1} \\
(\% \text { Reduction })\end{array}$ \\
\hline $\mathrm{SO}_{4}^{2-}$ & 19.47 & N.D. $(>99)$ \\
\hline$\Sigma$ Anions & 49.43 & $4.25(91.4)$ \\
\hline$\Sigma$ Cations & 39.26 & $6.04(84.6)$ \\
\hline \multicolumn{3}{|c|}{ SORPTION } \\
\hline meq anions/g HT3015OT & - & 4.45 \\
\hline meq cations/g HT3015OT & - & 3.23 \\
\hline $\begin{array}{c}\text { Maximum sorption } \\
\text { capacity } \\
\text { (in standard sulfate sol.): } \\
\text { meq } \mathrm{SO}_{4}^{2-} / \mathrm{g} \mathrm{HT} 3015 \mathrm{OT}\end{array}$ & & 3.85 \\
\hline $\begin{array}{c}\text { Real sorption capacity } \\
\text { (in water): } \\
\text { meq } \mathrm{SO}_{4}^{2-} / \mathrm{g} \text { HT3015OT }\end{array}$ & & 2.58 \\
\hline
\end{tabular}

derground water, particularly sulfate ions. Additionally the adsorbent decreases the hardness of water by removing the carbonate and sulfate ions, thereby lowering the amount of hardly soluble salts. The HTLC clays synthesized as part of this work have performed in an excellent manner for diminishing the relevant parameters of originally sulfurous water, below the limits set forth for drinking water according to the reference norm.

In terms of the HT3015O regenerating or recycling, it was shown that the repeating cycle calcination-rehydration-anion exchange allowed the clay to continue performing at stable efficiency $>75 \%$ of the original HTLC.

To date, little work has been done applying HT compounds to the treatment of groundwater. This work fulfilled the dual purpose of showing the effectiveness of the green chemistry proposed in generating the HTLC HT3015OT from waste products, as well as its novel application to the removal of sulfates from groundwater, avoiding the expense and complications associated with standard reverse osmosis methods by exploiting the capacity of HTLCs to be regenerated for multiple uses before losing their sorption efficiency. We believe this novel compound and application has an important implication to the future of industrial-scale water treatment options.

\section{Acknowledgements}

The authors thank ININ, ITT, UPAEP University, UNAM and BUAP for the technical work for the different characterization techniques. 


\section{REFERENCES}

[1] G. Rosano-Ortega, "Evaluación de Hidrotalcita Industrial Para el Tratamiento del Agua Sulfatada del Valle de Puebla," Master Degree Dissertation, Universidad Autónoma del Estado de México (UAEM), Toluca, 2003.

[2] S. J. Palmer, L. M. Grand and R. L Frost, "Thermal Analysis of Hydrotalcite Synthesized from Aluminate Solutions," Journal of Thermal Analysis and Calorimetry, Vol. 103, No. 2, 2011, pp. 473-478. doi:10.1007/s10973-010-1004-5

[3] S. J. Palmer, R. L. Frost and T. Nguyen, "Thermal Decomposition of Hydrotalcite with Molybdate and Vandate Anions in the Interlayer," Journal of Thermal Analysis and Calorimetry, Vol. 92, No. 3, 2008, pp. 879-886. doi:10.1007/s10973-007-8642-2

[4] G. Fetter, E. Ramos, M. T. Olguín, P. Bosch, T. López, and S. Bulbulian, "Sorption of ${ }^{131} \mathrm{I}^{-}$by Hydrotalcites," Journal of Radioanalytical and Nuclear Chemistry, Vol. 221, No. 1-2, 1997, pp. 63-66. doi:10.1007/BF02035243

[5] J. S. Wu, Y. K. Xiao, J. Y. Wan and L. R. Wen, "The Growth Mechanism of Hydrotalcite Crystal," Science China Technological Sciences, Vol. 55, No. 4, 2012, pp. 872-878.

[6] S. P. Newman, W. Jones, P. O'Connor and D. N. Stamires, "Synthesis of the $3 \mathrm{R}_{2}$ Polytype of a HydrotalciteLike Mineral," Journal of Materials Chemistry, Vol. 12, No. 2, 2002, pp. 153-155. doi:10.1039/b110715c

[7] H. Khaled and S. Ezzeddine, "Using Kaolinitic Clay for Preparation of a Hydrotalcite-Like Compound," Materials Sciences and Applications, Vol. 2, No. 6, 2011, pp. 684691.

[8] I. F. Alexa, R. F. Popovici and M. Ignat, "Non-Toxic Nanocomposite Containing Captopril Intercalated into Green Inorganic Carrier," Digest Journal of Nanomaterials and Biostructures, Vol. 6, No. 3, 2011, pp. 10911101.

[9] Z. Q. Yang, K.-M. Choi and N. Z. Jiang, "Microwave Synthesis of Hydrotalcite by Urea Hydrolysis," Bulletin of the Korean Chemical Society, Vol. 28, No. 11, 2007, pp. 2029-2033. doi:10.5012/bkcs.2007.28.11.2029

[10] V. Dávila, E. Lima, S. Bulbulian and P. Bosch, "Mixed $\mathrm{Mg}(\mathrm{Al}) \mathrm{O}$ Oxides Synthesized by the Combustion Method and Their Recrystallization to Hydrotalcites," Microporous and Mesoporous Materials, Vol. 107, No. 3, 2008, pp. 240-246. doi:10.1016/j.micromeso.2007.03.013

[11] T. W. Kim, M. Sahimi and T. T. Tsotsis, "Preparation of Hydrotalcite Thin Films Using an Electrophoretic Technique," Industrial \& Engineering Chemistry Research, Vol. 47, No. 23, 2008, pp. 9127-9132. doi:10.1021/ie071446s

[12] M. R. Othman, Z. Helwani, F. Martunus and W. J. N. Fernando, "Synthetic Hydrotalcites from Different Routes and Their Application as Catalysts and Gas Adsorbents: A Review," Applied Organometallic Chemistry, Vol. 23, No. 9, 2009, pp. 335-346. doi:10.1002/aoc.1517

[13] R. Salomao, L. M. Milena, H. H. Wakamatsu and V. C. Pandolfelli, "Hydrotalcite Synthesis via Co-Precipitation Reactions Using $\mathrm{MgO}$ and $\mathrm{Al}(\mathrm{OH})_{3}$ Precursors," Ceramics International, Vol. 37, No. 8, 2011, pp. 3063-3070.
[14] T. Qi, W. Z. Yin and L. Zhang, "Synthesis of Hydrotalcite Using Brucite as the Source of Magnesium," $A d$ vanced Materials Research, Vol. 158, 2011, pp. 241-247. doi:10.4028/www.scientific.net/AMR.158.241

[15] Y. Liu, E. Lotero, J. G. Goodwin and X. Mo, “Transesterification of Poultry Fat with Methanol Using Mg-Al Hydrotalcite Derived Catalysts," Applied Catalysis A: General, Vol. 331, 2007, pp. 138-148. doi:10.1016/j.apcata.2007.07.038

[16] S.-L. Wang and X.-M. Song, "Synthesize and Application of Mg-Al Hydrotalcite in Flame Retardant Paper Preparation," Advanced Materials Research, Vol. 174, 2011, pp. 362-365.

[17] M. Eisgruber, J. Ladebeck, J. Koy, H. Schiessling, W. Buckl and H. Ebert, "Method for the Production of Hydrotalcites," United State Patent No. 7, 2011, pp. 1-11.

[18] A. W. Nursulihatimarsyila, K. Y. Cheah, T. G. Chuah, W. L. Siew and T. S. Y. Choong, "Deoiling and Regeneration Efficiencies of Spent Bleaching," American Journal of Applied Sciences, Vol. 7, No. 3, 2010, pp. 434-437. doi:10.3844/ajassp.2010.434.437

[19] O. Meyer, F. Roessner, R. A. Rakoczy and R. W. Fischer, "Impact of Organic Interlayer Anions in Hydrotalcite Precursor on the Catalytic Activity of Hydrotalcite-Derived Mixed Oxides," ChemCatChem, Vol. 2, No. 3, 2010, pp. 314-321.

[20] Q. Zhang and F. Saito, "Novel Waste Processing by Means of Mechanochemical Treatment," Materials Science Forum, Vol. 561-565, 2007, pp. 1569-1573. doi:10.4028/www.scientific.net/MSF.561-565.1569

[21] American Public Health Association, "Standard Methods for the Examination of Water and Wastewater," 19th Edition, American Water Works Association, and Water Pollution Control Federation, American Public Health Association, Washington, 1995, p. 1050.

[22] A. Kawamoto, T. Suzuki, N. Kiba and T. Sato, "Regeneration and Reuse of Hydrotalcite-Like Anion Exchanger with High Selectivity to Phosphate Anion," Journal of the Society of Inorganic Materials, Japan, Vol. 10, 2003, pp. 167-172.

[23] K. František, E. Kovácsová and D. Koloušek, "Removal of Anions from Solution by Calcined Hydrotalcite and Regeneration of Used Sorbent in Repeated CalcinationRehydration-Anion Exchange Processes," Collection of Czechoslovak Chemical Communications, Vol. 64, No. 9, 2009, pp. 1517-1528.

[24] S. Miyata and A. Okada, "Synthesis of Hydrotalcite Like Compounds and Their Physico-Chemical PropertiesThe Systems $\mathrm{Mg}^{2+}-\mathrm{Al}^{3+}-\mathrm{SO}_{4}{ }^{2-}$ and $\mathrm{Mg}^{2+}-\mathrm{Al}^{3+}-\mathrm{CrO}_{4}{ }^{2-}$," Clays and Clay Minerals, Vol. 25, 1977, pp. 14-18. doi:10.1346/CCMN.1977.0250103

[25] E. Heraldy, S. J. Santosa and K. Wijaya, "Synthesis of $\mathrm{Mg} / \mathrm{Al}$ Hydrotalcite-Like from Brine Water and Its Application for Methyl Orange Removal: A Preliminary Study," Makara Science Serie, Vol. 15, 2011, pp. 9-14.

[26] G. Mondragón-Gutiérrez, D. Cruz, H. Pfeiffer and S. Bulbulian, "Low Temperature Synthesis of $\mathrm{Li}_{2} \mathrm{SiO}_{3}$ : Effect on Its Morphological and Textural Properties," Research 
Letters in Materials Science, Vol. 2008, 2008, pp. 1-4. doi: $10.1155 / 2008 / 908654$

[27] V. Rives, "Layered Double Hydroxides: Present and Future," Nova Science Publishers, Inc., New York, 2001, p. 350 .

[28] Z. Li, Y. Song, J. Wang, Q. Liu, P. Yang and M. Zhang, "Study of Structural Transformations and Phases Formation upon Calcination of Zn-Ni-Al Hydrotalcite Nanosheets," Bulletin of Materials Science, Vol. 34, No. 2, 2011, pp. 183-189. doi:10.1007/s12034-011-0060-1

[29] M. J. Kang, S. W. Rhee and H. Moon, "Sorption of $\mathrm{MO}^{4-}$ $(\mathrm{M}=\mathrm{Tc}, \mathrm{Re})$ on $\mathrm{Mg} / \mathrm{Al}$ Layered Double Hydroxide by Anion Exchange," Radiochimica Acta, Vol. 75, 1996, pp. 169-173.

[30] Federal Official Newspaper, "NOM-127-SSA1-1994," Health Secretariat, 1994. http://www.salud.gob.mx/unidades/cdi/nom/127ssa14.html

[31] M. S. Martínez-Gallegos, H. Pfeiffer, E. Lima, M. Espinosa, P. Bosch and S. Bulbulian, "Cr(VI) Immobilization in Mixed (Mg,Al) Oxides," Microporous and Mesoporous Materials, Vol. 94, No. 1-3, 2006, pp. 234-242.

[32] L. M. Parker, N. B. Milestone and R. H. Newman, "The Use of Hydrotalcite as an Anion Absorbent," Industrial \& Engineering Chemistry Research, Vol. 34, No. 4, 1995, pp. 1196-1202. doi:10.1021/ie00043a023

[33] S. A. Exyco, "Geohydrological Aquifer Study of Puebla Valley," Management Studies and Projects of the National Water Commission and Ministry of Agriculture and Water Resources, Mexico, 1990. 